\title{
The impacts of baseline ventilator parameters on hospital mortality in acute respiratory distress syndrome treated with venovenous extracorporeal membrane oxygenation: a retrospective cohort study
}

\author{
Meng-Yu Wu ${ }^{1,2^{*}} \mathbb{B}$, Yu-Sheng Chang ${ }^{1}$, Chung-Chi Huang ${ }^{3}$, Tzu-I Wu $\mathbf{W}^{4,5}$ and Pyng-Jing Lin ${ }^{1}$
}

\begin{abstract}
Background: Venovenous extracorporeal membrane oxygenation (W-ECMO) is a valuable life support in acute respiratory distress syndrome (ARDS) in adult patients. However, the success of W-ECMO is known to be influenced by the baseline settings of mechanical ventilation (MV) before its institution. This study was aimed at identifying the baseline ventilator parameters which were independently associated with hospital mortality in non-trauma patients receiving W-ECMO for severe ARDS.
\end{abstract}

Methods: This retrospective study included 106 non-trauma patients (mean age: 53 years) who received W-ECMO for ARDS in a single medical center from 2007 to 2016. The indication of W-ECMO was severe hypoxemia $\left(\mathrm{P}_{\mathrm{a}} \mathrm{O}_{2} /\right.$ $\mathrm{FiO}_{2}$ ratio $<70 \mathrm{mmHg}$ ) under pressure-controlled $\mathrm{MV}$ with peak inspiratory pressure $(\mathrm{PIP})>35 \mathrm{cmH}_{2} \mathrm{O}$, positive endexpiratory pressure (PEEP) $>5 \mathrm{cmH}_{2} \mathrm{O}$, and $\mathrm{F}_{i} \mathrm{O}_{2}>0.8$. Important demographic and clinical data before and during $\mathrm{W}$-ECMO were collected for analysis of hospital mortality.

Results: The causes of ARDS were bacterial pneumonia $(n=41)$, viral pneumonia $(n=24)$, aspiration pneumonitis $(n=3)$, and others $(n=38)$. The median duration of MV before ECMO institution was 3 days and the overall hospital mortality was $53 \%(n=56)$. The medians of $\mathrm{PaO}_{2} / \mathrm{FiO}_{2}$ ratio, PIP, PEEP, and dynamic pulmonary compliance $\left(\mathrm{PC}_{\text {dyn }}\right)$ at the beginning of $\mathrm{MV}$ were $84 \mathrm{mmHg}, 32 \mathrm{cmH}_{2} \mathrm{O}, 10 \mathrm{cmH}_{2} \mathrm{O}$, and $21 \mathrm{~mL} / \mathrm{cmH}_{2} \mathrm{O}$, respectively. However, before the beginning of $\mathrm{W}-\mathrm{ECMO}$, the medians of $\mathrm{PaO}_{2} / \mathrm{FiO}_{2}$ ratio, $\mathrm{PIP}, \mathrm{PEEP}$, and $\mathrm{PC}_{\text {dyn }}$ became $69 \mathrm{mmHg}, 36 \mathrm{cmH}_{2} \mathrm{O}, 14$ $\mathrm{cmH}_{2} \mathrm{O}$, and $19 \mathrm{~mL} / \mathrm{cmH}_{2} \mathrm{O}$, respectively. The escalation of PIP and the declines in $\mathrm{PaO}_{2} / \mathrm{FiO}_{2}$ ratio and $\mathrm{PC}_{\text {dyn }}$ were significantly correlated with the duration of MV before ECMO institution. Finally, the duration of MV (OR: 1.184, 95\% $\mathrm{Cl}: 1.079-1.565, p<0.001)$ was found to be the only baseline ventilator parameter that independently affected the hospital mortality in these ECMO-treated patients.

Conclusion: Since the duration of MV before ECMO institution was strongly correlated to the outcome of adult respiratory $\mathrm{ECMO}$, medical centers are suggested to find a suitable prognosticating tool to determine the starting point of respiratory ECMO among their candidates with different duration of MV.

(Continued on next page)

\footnotetext{
* Correspondence: david3627@gmail.com

'Department of Cardiovascular Surgery, Chang Gung Memorial Hospital and

Chang Gung University, Taoyuan, Taiwan

${ }^{2}$ School of Traditional Chinese Medicine, Chang Gung University, Taoyuan,

Taiwan

Full list of author information is available at the end of the article
} 
(Continued from previous page)

Trial registration: This study reported a health care intervention on human participants and was retrospectively registered. The Chang Gung Medical Foundation Institutional Review Board approved the study (no. 201601483B0) on November 23, 2016. All of the data were extracted from December 1, 2016, to January 31, 2017.

Keywords: Venovenous extracorporeal membrane oxygenation, Adult respiratory distress syndrome, Lung recruitment, Lung-protective mechanical ventilation

\section{Background}

Extracorporeal Membrane Oxygenation (ECMO) is currently an important life support for acute respiratory distress syndrome (ARDS) in adult patients $[1,2]$. According to the 2016 international report of the Extracorporeal Life Support Organization (ELSO) Registry, 58\% of the adult patients receiving ECMO for severe respiratory failure can be saved and discharged from hospital [3]. This report also reveals that about $90 \%$ of the 9812 ECMO runs for adult respiratory failure are in venovenous (VV)-associated configurations [3]. The niche of VV-ECMO in the management of ARDS is to provide a pre-pulmonary blood gas exchange to the venous blood and reduce the patient's dependence on pulmonary ventilation [2].While the patient's dependence on pulmonary ventilation is reduced, the risk and the severity of ventilator-induced lung injury (VILI) can theoretically be mitigated. Although the popularity of adult respiratory ECMO is continuously increasing, the applications of ECMO are still limited in large medical centers and reserved for the most advanced diseases [1]. The discrepancy in user experience leads to considerable controversies about the timing of respiratory ECMO among experts worldwide. Currently, the timing of respiratory ECMO is mostly determined by the severity of hypoxemia which is represented by the ratio of arterial oxygen tension $\left(\mathrm{PaO}_{2}\right)$ to the fraction of inspired oxygen $\left(\mathrm{FiO}_{2}\right)$ under mechanical ventilation (MV). In the ELSO Guidelines for Adult Respiratory Failure, the suggested threshold value of $\mathrm{PaO}_{2} / \mathrm{FiO}_{2}$ (PF) ratio for ECMO institution is $100 \mathrm{mmHg}$ or less [4]. However, under the inclusion criteria based on PF ratio, patients with a relatively slow-progressive disease may experience a significant escalation in the driving force of MV before their PF ratio can finally meet the threshold value for ECMO [5]. Since the therapeutic goal of respiratory ECMO is to reduce the negative influence of $\mathrm{MV}$ on the success of adult respiratory ECMO, the starting point of respiratory ECMO should also take the determinant ventilator parameters into consideration. Therefore, the study was aimed at identifying the baseline ventilator parameters which were independently associated with hospital mortality in patients receiving VV-ECMO for severe ARDS.

\section{Methods}

Settings and patients

From March 2007 to March 2016, a total of 151 adult patients received VV-ECMO for advanced respiratory support at Chang Gung Memorial Hospital Linko Branch. The university-affiliated hospital is a tertiary referral center with 3400 beds. To avoid the influences of trauma or surgery on blood coagulation and compliance of the respiratory system, we only enrolled 106 adult non-trauma patients who had a single run of VV-ECMO and survived on VV-ECMO $>24 \mathrm{~h}$ in this retrospective study. This study was conducted in accordance with the amended Declaration of Helsinki. The ethics committee of the Chang Gung Medical Foundation approved this protocol (CGMF IRB no. 201601483B0) and waived the necessity of individual patient consent.

\section{Managements of adult VV-ECMO}

Our techniques of applying MV and ECMO to improve hypoxemia in patients with ARDS were described previously [5-9]. Before ECMO is considered, patients with ARDS were treated with the lung-protective MV and paralyzed with neuromuscular blockers. Our lungprotective $\mathrm{MV}$ is pressure-controlled ventilation which uses a peak airway pressure (PIP) less than $35 \mathrm{mmHg}$ to drive a tidal volume $\left(\mathrm{V}_{\mathrm{T}}\right)$ no more than $6 \mathrm{ml} / \mathrm{kg}$. To prevent carbon dioxide $\left(\mathrm{CO}_{2}\right)$ retention and oxygen toxicity, the respiratory rate, the positive end-expiratory pressure (PEEP), and the $\mathrm{F}_{\mathrm{i}} \mathrm{O}_{2}$ of $\mathrm{MV}$ are set at 20 to 25/ min, 10 to $18 \mathrm{cmH}_{2} \mathrm{O}$, and less than 0.8 , respectively. VVECMO would be delivered to suitable candidates if they required a higher PIP and $\mathrm{FiO}_{2}$ for maintaining a PF not less than $70 \mathrm{mmHg}$. Nevertheless, VV-ECMO was contraindicated in candidates showing (1) uncontrolled hemorrhages, (2) major brain damages, and (3) significant hemodynamic instability. The definition of significant hemodynamic instability here was circulatory shock (systolic arterial blood pressure $<90 \mathrm{mmHg}$ ) that required a high-dosed inotrope/vasopressor therapy (dopamine $>15$ $\mathrm{mcg} / \mathrm{kg} / \mathrm{min}$, epinephrine $>0.1 \mathrm{mcg} / \mathrm{kg} / \mathrm{min}$, or norepinephrine $>0.1 \mathrm{mcg} / \mathrm{kg} / \mathrm{min}$ ). Our ECMO devices include a centrifugal pump [Capiox emergent bypass system (Terumo, Tokyo, Japan) or Bio-console 560 system (Medtronic, Minneapolis, MN, USA)], an oxygenator with silicone membrane (Medtronic, Minneapolis, MN, USA) 
or polymethylpentene membrane (Terumo Capiox-SX or Medos Hilite 7000), and two vascular cannulae (DLP Medtronic, Minneapolis, MN, USA). We conduct VVECMO via percutaneous cannulation of the common femoral vein (inflow, with a cannula of 19-23 French) and the right internal jugular vein (outflow, with a cannula of 17-21 French). After implantation of VVECMO, we initially maximize the sweep gas flow $(10 \mathrm{~L} /$ min, pure oxygen) to rapidly remove $\mathrm{CO}_{2}$, and gradually increase the ECMO pump flow to achieve a steady flow that carries the best pulse oximetry-detected oxyhemoglobin saturation $\left(\mathrm{SpO}_{2}\right)$. To rest the injured lungs, we gradually downgrade the original MV settings to a noninjurious level ( $\mathrm{PIP} \leq 30 \mathrm{cmH}_{2} \mathrm{O}$ and $\mathrm{MV} \mathrm{FiO}_{2} \leq 0.4$ ). According to the data of arterial and post-oxygenator blood gas samplings, we dynamically adjust the flows of ECMO to provide an optimal $\mathrm{SpO}_{2}(>90 \%)$ and arterial oxyhemoglobin saturation $\left(\mathrm{SaO}_{2} ;>85 \%\right)$. A modest anticoagulation (activated partial thromboplastin time between 40 and 55 s) is achieved with systemic heparinization except in hemorrhagic patients. We would try to wean the improved patients from VV-ECMO as long as the arterial oxygenation could be maintained with small $\mathrm{V}_{\mathrm{T}}$ and ventilator $\mathrm{FiO}_{2}$ no more than 0.6.

\section{Data collection}

We retrospectively reviewed the electronic medical records of every patient and collected their relevant demographic and clinical data before and during ECMO run. Since sequential organ failure assessment (SOFA) score [10] and respiratory extracorporeal membrane oxygenation survival prediction (RESP) score [11] have become our major prognosticating tools for adult respiratory ECMO now, we collected the essential data to calculate the two scores in each patient. Therefore the following variables were collected: age, gender, body weight and height, acute respiratory diagnosis (viral pneumonia, bacterial pneumonia, asthma, trauma/burn, aspiration, and others), immunocompromised status (malignancy, organ transplantation, liver cirrhosis Child $\mathrm{B}$ or $\mathrm{C}$, or autoimmune diseases requiring long-term immunosuppressive therapy), non-pulmonary infection, duration of MV before institution of VV-ECMO, MV settings [measured ventilation volume, PIP, mean airway pressure (MAP), PEEP, dynamic driving pressure, dynamic pulmonary compliance $\left(\mathrm{PC}_{\mathrm{dyn}}\right)$, and oxygen index (OI)] soon (1 to $2 \mathrm{~h}$ ) after institution of $\mathrm{MV}$ and just $(1-2 \mathrm{~h})$ before institution of VV-ECMO, special medications (neuromuscular blockers, bicarbonate or vasopressors) before institution of VV-ECMO, the latest results of blood tests (arterial blood gas sampling, blood cell counts, creatinine, and total bilirubin) before institution of VV-ECMO, durations of hospital and ECMO stay, and outcomes (survived or died in hospital). In the survivors, we also collected the MV settings just before and after $24 \mathrm{~h}$ of ECMO removal. The $\mathrm{V}_{\mathrm{T}}$ was defined as the measured ventilation volume dividing by the ideal body weight. The dynamic driving pressure was defined as the difference of PIP and PEEP. $\mathrm{PC}_{\mathrm{dyn}}$ was defined as the measured ventilation volume dividing by the difference of PIP and PEEP. The OI was defined as the product of $\mathrm{MAP}$ and $\mathrm{FiO}_{2}$ dividing by $\mathrm{PaO}_{2}$. The baseline value of a given variable was the value obtained just before institution of VV-ECMO. For our practical purposes, we made some modifications of the definitions in the original RESP score. First, we assigned the patients with fungal pneumonia to the category of bacterial pneumonia, because fungal pneumonia was not a category of diagnosis in RESP score and the number of fungal pneumonia in our patient cohort was small. Second, we excluded the item of nitric oxide inhalation because this information was often missing in our patient cohort. Third, we assigned a SOFA neurological assessment score to each patient according to his/her neurological status before sedation [12].

\section{Outcome measures}

The endpoint of this study was to identify the predictors of hospital mortality in adult respiratory ECMO among the baseline ventilator parameters.

\section{Statistical analyses}

Statistical analyses were performed with SPSS for Windows (Version 21, IBM, Inc., NY, USA). For all analyses, the statistical significance was set at $p<0.05$. The independent T-test or the Mann-Whitney $U$ test was used for univariate comparison of numerical variables. The Chi-square or Fisher's exact test was used for univariate comparison of categorical variables. The data were presented as mean ( \pm standard deviation) for numerical variables with normal distribution or median (interquartile range; IQR) for numerical variables without normal distribution. The categorical data were presented as number (percentage). The multivariate logistic regression method was used to identify the independent predictors of hospital mortality and to build up the mortality risk prediction model. All variables with a $p<0.05$ in univariate tests were firstly processed by the logistic regression method with a backward stepwise selection procedure. The variables showed a $p<0.05$ in the logistic regression process were re-tested by the logistic regression method with a forward stepwise selection procedure to build the final prediction model. The final model was evaluated by the Hosmer-Lemeshow test and the receiver operating characteristic curve analysis for its goodness-of-fit and the predictive power for hospital mortality. 


\section{Results}

\section{Patient characteristics}

Our therapeutic protocol and associated patient distribution are presented in fig. 1. The results of univariate comparisons of important demographic and clinical data between the survivors and the non-survivors are presented in Table 1. The causes of ARDS were categorized into 4 groups: bacterial pneumonia $(n=41$; three were fungal pneumonia, and the top three found bacteria were Staphylococcus aureus, Pseudomonas aeruginosa, and Acinetobacter baumannii), viral pneumonia $(n=24$; all influenza type A), aspiration pneumonitis $(n=3)$, and others $(n=38)$. The "others" group included (1) pneumonia without identifiable pathogens $(n=24)$; (2) pulmonary hemorrhage caused by autoimmune vasculitis $(n=2)$; (3) pneumonia after near-drowning $(n=1)$; and (4) pulmonary edema due to acute on chronic renal failure $(n=4)$, acute pancreatitis $(n=3)$, or after percutaneous interventions $(n=4 ; 3$ for cardiac lesions and 1 for cerebral aneurysm). All patients received VVECMO in our institution. Three patients received MV support before they were transferred to our hospital, and the duration of MV support before their ER admission were $10 \mathrm{~h}, 18 \mathrm{~h}$, and 4 days. Diagnoses in the 37

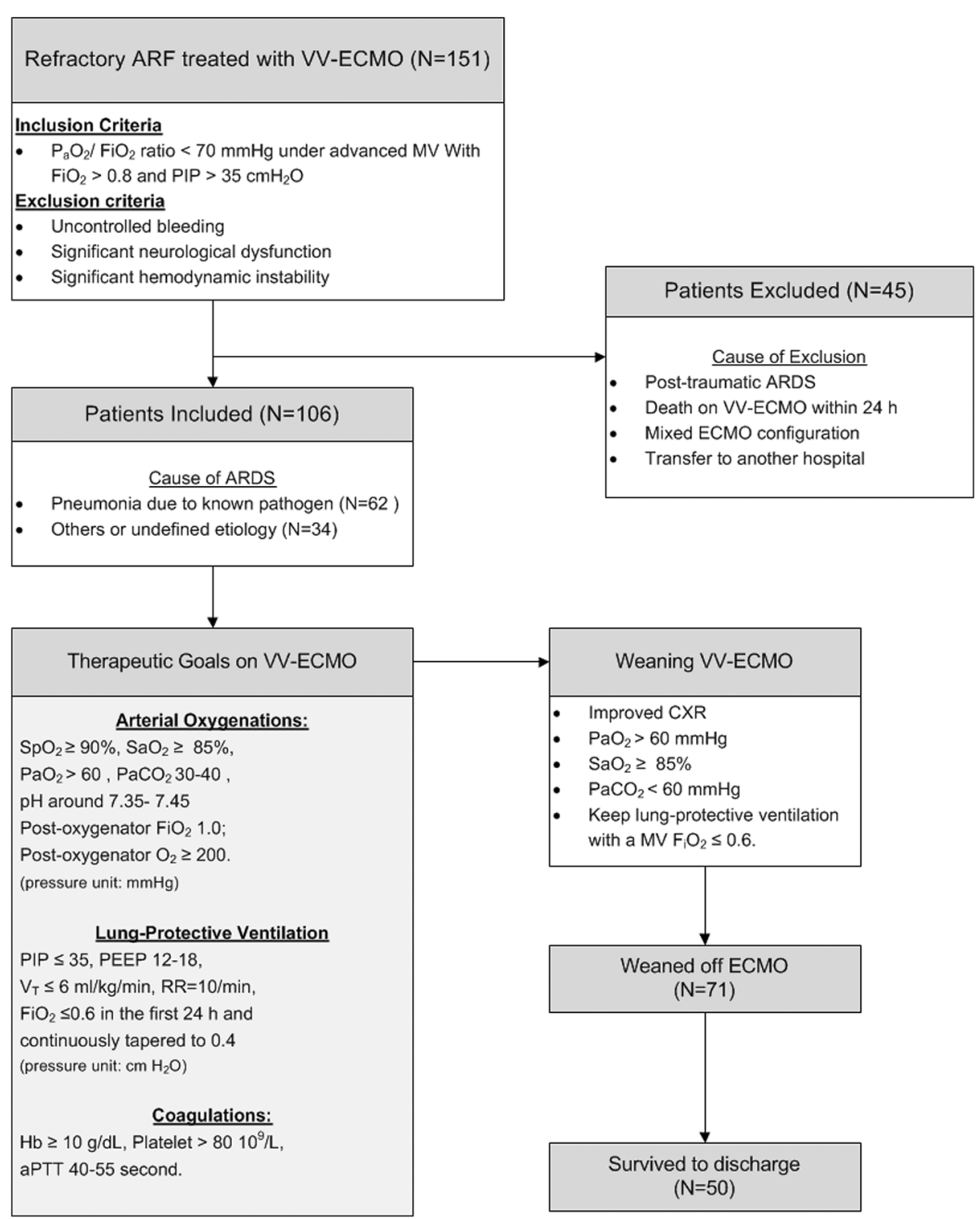

Fig. 1 Flow chart of patient distribution and managements during venovenous extracorporeal membrane oxygenation. ARF: Acute respiratory failure. FiO2: The fraction of inspired oxygen. PaO2: Arterial oxygen tension. PEEP: Positive end-expiratory pressure. PIP: Peak inspiratory pressure. RR: Respiratory rate. SaO2: Arterial oxygen saturation; SpO2: Oxyhemoglobin saturation by pulse oximetry. $\mathrm{V}_{\mathrm{T}}$ : Tidal volume. W-ECMO: Venovenous extracorporeal membrane oxygenation 
Table 1 Patient characteristics before venovenous extracorporeal membrane oxygenation

\begin{tabular}{|c|c|c|c|c|}
\hline & $\begin{array}{l}\text { All } \\
(n=106)\end{array}$ & $\begin{array}{l}\text { Survivor } \\
(n=50)\end{array}$ & $\begin{array}{l}\text { Non-survivor } \\
(n=56)\end{array}$ & $P$ \\
\hline Age (year) & $53 \pm 15$ & $51 \pm 15$ & $55 \pm 15$ & 0.11 \\
\hline Male & $71(67)$ & $35(70)$ & $36(64)$ & 0.53 \\
\hline Predicted body weight ${ }^{a}(\mathrm{~kg})$ & $55 \pm 14$ & $55 \pm 16$ & $55 \pm 11$ & 0.89 \\
\hline Hospital day before ECMO & $6(1-14)$ & $2(1-9)$ & 11(4-20) & $<0.001^{*}$ \\
\hline Mechanical ventilation before ECMO (day) & $3(1-9)$ & $1(0-4)$ & $6(1-12)$ & $<0.001^{*}$ \\
\hline \multicolumn{5}{|l|}{ Cause of ARDS } \\
\hline Viral pneumonia & $24(21)$ & $11(22)$ & $13(23)$ & 0.88 \\
\hline Bacterial pneumonia & $38(37)$ & $16(32)$ & $22(39)$ & 0.54 \\
\hline Fungal pneumonia & $3(3)$ & 0 & $3(6)$ & 0.25 \\
\hline Aspiration pneumonitis & $3(3)$ & $3(6)$ & 0 & 0.10 \\
\hline Other acute respiratory diagnoses & $38(36)$ & $20(40)$ & $18(32)$ & 0.40 \\
\hline Acute associated infection & $24(21)$ & $11(22)$ & $13(23)$ & 0.88 \\
\hline Immunocompromised status ${ }^{b}$ & $37(35)$ & $11(22)$ & $26(46)$ & $0.008^{*}$ \\
\hline Renal failure requiring dialysis & $28(26)$ & $13(26)$ & $15(27)$ & 0.93 \\
\hline Creatinine (mg/dL) & $1.6(0.8-3.4)$ & $2.8 \pm 3.3$ & $2.3 \pm 2.3$ & 0.36 \\
\hline Total bilirubin (mg/dL) & $1.5 \pm 2.5$ & $1.1 \pm b 1.2$ & $1.9 \pm 3.2$ & 0.14 \\
\hline Platelet count $\left(10^{9} / \mathrm{L}\right)$ & $137(83-218)$ & $172(113-237)$ & $106(60-161)$ & $0.002^{*}$ \\
\hline Hemoglobin (g) & $10(9-12)$ & $11(9-12)$ & $10(9-11)$ & 0.08 \\
\hline SOFA score & $10(8-11)$ & $9(7-10)$ & $10(9-12)$ & $0.002^{*}$ \\
\hline RESP score & $2 \pm 3$ & $2 \pm 3$ & $1 \pm 3$ & $0.05^{*}$ \\
\hline
\end{tabular}

Data were presented as mean \pm standard deviation in normal-distributed numerical variables, median (interquartile range) in numerical variables not normal-distributed, and $n(\%)$ in categorical variables. ECMO Extracorporeal membrane oxygenation, SOFA sequential organ failure assessment, RESP score Respiratory extracorporeal membrane oxygenation survival prediction score, ARDS Acute respiratory distress syndrome. ${ }^{a}$ Ideal body weight is calculated by the ARDSnet formulas. ${ }^{b}$ Immunocompromised status includes hematologic malignancy, solid tumor, solid organ transplantation, liver cirrhosis Child B or $C$, or autoimmune diseases requiring long-term immunosuppressive therapy

${ }^{*} p<0.05$. (in the comparisons between survivors and non-survivors)

immunocompromised patients were malignancies $(n=16$; 15 solid tumor and 1 lymphoma), autoimmune diseases ( $n$ =10; 2 dermatomyositis, 2 idiopathic thrombocytopenia, 2 granulomatosis with polyangiitis, 1 psoriatic arthritis, 1 rheumatoid arthritis, 1 systemic lupus erythematosus, and 1 Graves'disease), immunosuppressive therapy in solid organ transplantation $(n=8 ; 6$ liver transplantation and 2 renal transplantation), advanced liver cirrhosis $(n=2)$, and steroid therapy in asthma $(n=1)$. Fifty-six patients died in hospital and 35 of them died on VV-ECMO. Six patients died on VV-ECMO due to hemorrhagic complications including intracranial hemorrhages $(n=2)$, intra-abdominal or retroperitoneal hemorrhages $(n=1)$, and gastrointestinal tract hemorrhages $(n=4)$. The multiple-organ failure syndrome with sepsis was the cause of death for the other non-survivors. The results of univariate comparisons of ventilator parameters between the survivors and nonsurvivors are also presented in Table 2. These parameters were obtained soon after the beginning of MV and just before the beginning of VV-ECMO. The 3 patients receiving MV support in other hospital were excluded from the analysis of ventilator parameters just after the beginning of
MV. Differences between the pre-ECMO and the early MV data of a given ventilator parameter were also calculated to present the deterioration of pulmonary function and the corresponding escalation of ventilation pressures before ECMO institution.

\section{Multivariate prediction model of hospital death}

According to the results of multivariate analysis, the pre-ECMO duration of MV [Odd ratio (OR): 1.184; 95\% confident interval (CI): 1.079-1.565, $p<0.001]$ and the pre-ECMO SOFA score (OR: 1.299; 95\% CI: $1.077-$ 1.302; $p=0.006)$ were identified to be the independent predictors of hospital mortality in adult non-trauma patients who received VV-ECMO for severe ARDS. The mortality prediction model built with these factors was presented as follows: Predicted mortality $(y)=e^{\mathrm{X}} /(1$ $\left.+\mathrm{e}^{\mathrm{X}}\right) \cdot \mathrm{X}=-3.218+0.169 \times($ days of MV before institution of VV-ECMO) $+0.262 \times$ (SOFA score before institution of VV-ECMO). The model explained 30\% (Nagelkerke $\mathrm{R}^{2}$ ) of the variance in hospital mortality and correctly classified $68.9 \%$ of the cases (sensitivity: 66.1\%; specificity: $72 \%$ ). This predictive model also 
Table 2 Ventilator parameters before venovenous extracorporeal membrane oxygenation

\begin{tabular}{|c|c|c|c|c|}
\hline & $\begin{array}{l}\text { All } \\
(n=106)\end{array}$ & $\begin{array}{l}\text { Survivor } \\
(n=50)\end{array}$ & $\begin{array}{l}\text { Non-survivor } \\
(n=56)\end{array}$ & $P$ \\
\hline \multicolumn{5}{|l|}{ Just after intubation } \\
\hline $\mathrm{P}_{\mathrm{a}} \mathrm{O}_{2} / \mathrm{F}_{\mathrm{i}} \mathrm{O}_{2}(\mathrm{mmHg})$ & $112 \pm 76$ & $90 \pm 55$ & $129 \pm 85$ & $0.009^{*}$ \\
\hline Peak inspiratory pressure $\left(\mathrm{cmH}_{2} \mathrm{O}\right)$ & $33 \pm 6$ & $32 \pm 5$ & $33 \pm 6$ & 0.86 \\
\hline Mean airway pressure $\left(\mathrm{cmH}_{2} \mathrm{O}\right)$ & $18 \pm 4$ & $18 \pm 4$ & $18 \pm 5$ & 0.85 \\
\hline PEEP $\left(\mathrm{cmH}_{2} \mathrm{O}\right)$ & $12 \pm 3$ & $12 \pm 3$ & $12 \pm 3$ & 0.56 \\
\hline Dynamic driving pressurea ${ }^{\mathrm{a}}\left(\mathrm{cmH}_{2} \mathrm{O}\right)$ & $21 \pm 5$ & $21 \pm 5$ & $22 \pm 5$ & 0.86 \\
\hline Measured tidal volume (ml/kg) & $7.7 \pm 2.3$ & $7.7 \pm 2.3$ & $7.8 \pm 2.3$ & 0.73 \\
\hline Dynamic compliance $\left(\mathrm{ml} / \mathrm{cmH}_{2} \mathrm{O}\right)$ & $22 \pm 9$ & $23 \pm 10$ & $21 \pm 8$ & 0.15 \\
\hline Oxygen index & $25 \pm 19$ & $29 \pm 22$ & $21 \pm 15$ & 0.11 \\
\hline \multicolumn{5}{|l|}{ Just before ECMO } \\
\hline $\mathrm{P}_{\mathrm{a}} \mathrm{O}_{2} / \mathrm{F}_{\mathrm{i}} \mathrm{O}_{2}(\mathrm{mmHg})$ & $72 \pm 17$ & $72 \pm 19$ & $72 \pm 16$ & 0.93 \\
\hline Peak inspiratory pressure $\left(\mathrm{cmH}_{2} \mathrm{O}\right)$ & $36 \pm 6$ & $35 \pm 5$ & $37 \pm 6$ & 0.16 \\
\hline Mean airway pressure $\left(\mathrm{cmH}_{2} \mathrm{O}\right)$ & $21 \pm 4$ & $21 \pm 4$ & $22 \pm 4$ & 0.13 \\
\hline PEEP $\left(\mathrm{cmH}_{2} \mathrm{O}\right)$ & $14 \pm 3$ & $14 \pm 3$ & $14 \pm 3$ & 0.79 \\
\hline Dynamic driving pressure $\left(\mathrm{cmH}_{2} \mathrm{O}\right)$ & $22 \pm 6$ & $21 \pm 5$ & $23 \pm 6$ & 0.22 \\
\hline Measured tidal volume (ml/kg) & $6.7(6-7.8)$ & $6.8(6.1-8.7)$ & $6.7(5.8-7.7)$ & 0.22 \\
\hline Dynamic compliance $\left(\mathrm{ml} / \mathrm{cmH}_{2} \mathrm{O}\right)$ & $19(15-23)$ & $21(15-25)$ & $17(12-21)$ & $0.01^{*}$ \\
\hline Oxygen index ${ }^{c}$ & $39 \pm 13$ & $39 \pm 14$ & $38 \pm 13$ & 0.66 \\
\hline \multicolumn{5}{|l|}{ Difference } \\
\hline$\Delta \mathrm{P}_{\mathrm{a}} \mathrm{O}_{2} / \mathrm{F}_{\mathrm{i}} \mathrm{O}_{2}(\mathrm{mmHg})$ & $-16(-71-9)$ & $0(-51-21)$ & $-31(-95-5)$ & $0.009^{*}$ \\
\hline$\triangle$ Peak inspiratory pressure $\left(\mathrm{cmH}_{2} \mathrm{O}\right)$ & $4 \pm 6$ & $4 \pm 6$ & $4 \pm 7$ & 0.18 \\
\hline$\triangle \mathrm{PEEP}\left(\mathrm{cmH}_{2} \mathrm{O}\right)$ & $3 \pm 4$ & $3 \pm 3$ & $3 \pm 4$ & 0.92 \\
\hline$\Delta$ Dynamic driving pressure ${ }^{\mathrm{a}}\left(\mathrm{cmH}_{2} \mathrm{O}\right)$ & $1 \pm 6$ & $1 \pm 6$ & $1 \pm 7$ & 0.33 \\
\hline$\Delta$ Measured tidal volume $(\mathrm{ml} / \mathrm{kg})$ & $-0.3(-1.9-0.8)$ & $0(-1.5-1.2)$ & $-0.8(-1.9-0.2)$ & $0.05^{*}$ \\
\hline$\Delta$ Dynamic compliance $^{\mathrm{b}}\left(\mathrm{ml} / \mathrm{cmH}_{2} \mathrm{O}\right)$ & $-2 \pm 11$ & $-1 \pm 11$ & $-3 \pm 11$ & 0.72 \\
\hline$\Delta$ Oxygen index ${ }^{c}$ & $14 \pm 2$ & $10 \pm 21$ & $17 \pm 19$ & 0.35 \\
\hline
\end{tabular}

Data were presented as mean \pm standard deviation in normal-distributed numerical variables, median (interquartile range) in numerical variables not normal-distributed, and $\mathrm{n}(\%)$ in categorical variables. ECMO Extracorporeal membrane oxygenation, PEEP Positive end expiratory pressure. ${ }^{a}$ Driving pressure $=($ Peak inspiratory pressure Positive end-expiratory pressure)

${ }^{\mathrm{b}}$ Dynamic pulmonary compliance $=$ Measured tidal volume/ Driving pressure

${ }^{c}$ Oxygen index $=$ [(Mean airway pressure $\left.\square \mathrm{X} \square \mathrm{FiO}_{2} \square \mathrm{X} 100\right) /$ arterial oxygen tension]

${ }^{*} p<0.05$. $\Delta$ : The data obtained before ECMO - the data obtained after intubation

fitted the dataset well (Hosmer-Lemeshow test: $\chi^{2}=$ 7.526, $p=0.376)$ and showed a fair predictive power of hospital mortality (c-index: $0.763, p<0.001,95 \%$ CI: 0.674-0.851). Figure 2 demonstrates the observed hospital mortality rates among patients grouped by their baseline SOFA score.

\section{Serial changes of arterial oxygenation during the course of treatment}

To get a deeper understanding of the influences of VVECMO combining lung-protective MV on arterial oxygenation during the course of treatment, we collected the ventilator parameters at several time points (T0: 1 to $2 \mathrm{~h}$ after intubation for MV, T1: 1 to $2 \mathrm{~h}$ before ECMO cannulation, T2:24 h after ECMO institution, T3: 1 to
$2 \mathrm{~h}$ before ECMO decannulation, and T4: $24 \mathrm{~h}$ after ECMO removal) for analysis and the results are demonstrated in Table 3. It is notable that only the survivors could go through the whole treatment and show data in all of the 5 points. The survivors' trends of PF ratio and dynamic driving pressure are also illustrated in fig. 3.

\section{Discussion}

This study revealed that the duration of MV before ECMO institution was the only baseline ventilator parameter which was independently associated with hospital mortality in non-trauma patients receiving VVECMO for severe ARDS, although the mechanism of how a prolonged duration of MV could jeopardize the survival in these ECMO-treated patients was still 


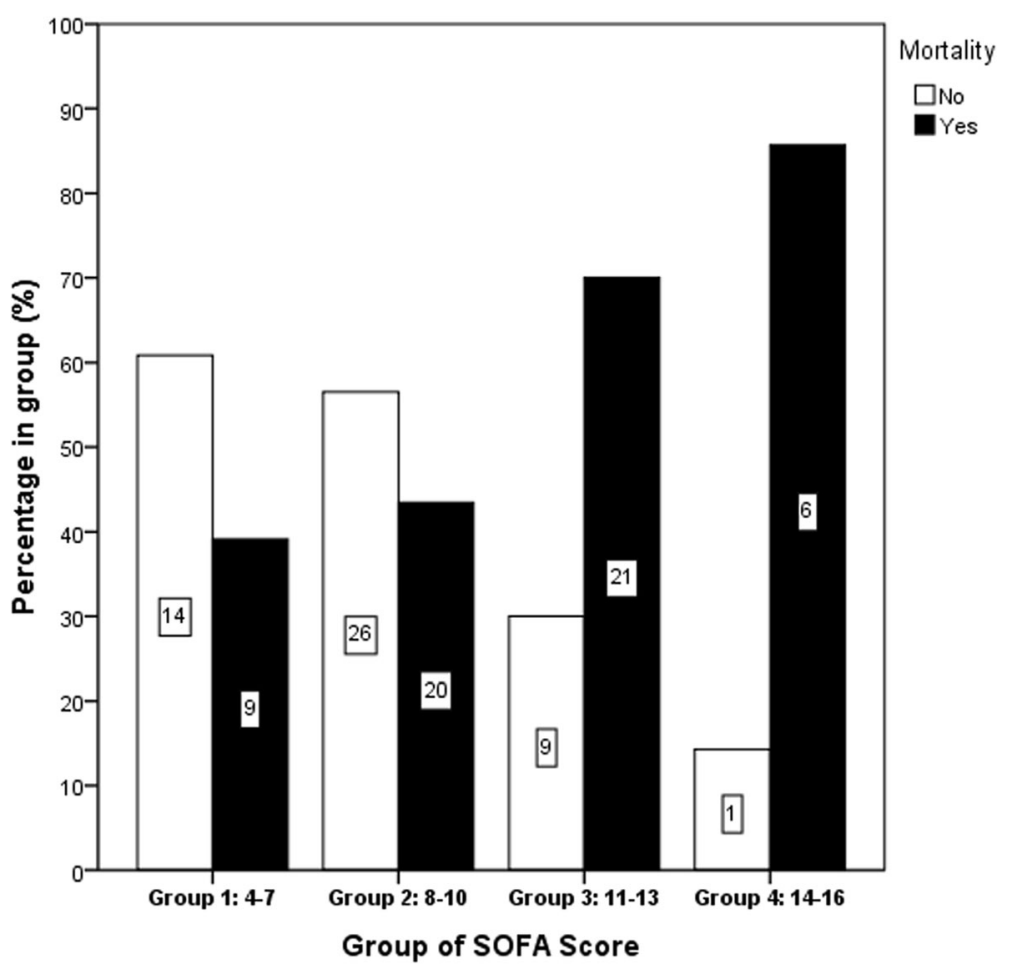

Fig. 2 Observed mortality rates among patients categorized by the baseline sequential organ failure assessment (SOFA) score. The case number in each group is also presented

unclear. In fact, this duration is a reciprocal measure of the declining rate of $\mathrm{PF}$ ratio from the value obtained at the beginning of MV to the given threshold value for ECMO. Clinically, this declining rate of PF ratio is significantly affected by the etiology of ARDS, patient characteristics, and the institutional experience on advanced modes of $\mathrm{MV}$, as the conclusion of CESAR trial $[11,13]$. These uncertainties make the suitable duration of MV before ECMO individualized among institutions. Nevertheless, limitation of this duration should still be important to adult candidates of respiratory ECMO. According to Table 2, regardless of the value of initial PF ratio, most of our patients were found to have severely non-compliant lungs at the beginning of $\mathrm{MV}$. The mean $\mathrm{PC}_{\mathrm{dyn}}$ measured at the beginning of $\mathrm{MV}$ was $22 \mathrm{~cm} \mathrm{H}_{2} \mathrm{O}$ in all of the patients, which was only accounted for $10 \%$ or less of the normal value [14]. This finding implied that these patients were very sensitive and vulnerable to the cyclic pulmonary manipulation of MV [15-17]. When the disease progresses and involves more pulmonary segments, clinicians often need to open the collapsed segments with an increased driving pressure of MV to maintain an acceptable blood-gas exchange. This attempt of lung recruitment may considerably increase the amount of dead space ventilation rather than effectively improve the blood-gas exchange, since the local perfusion of the distended segments may drop, as demonstrated by Gattinoni et al. [18]. The over-distended lungs may also increase the intrathoracic pressure and compromise the cardiac output [19]. Therefore, if available and not contraindicated, VV-ECMO combining lung-protective MV is a valuable strategy to reduce pulmonary manipulation and reverse some of the pulmonary segments performing dead space ventilation under high-pressure MV to the segments performing effective blood-gas exchange under a reduced inspiratory pressure. However, the benefit of VV-ECMO is often small in patients with prolonged ventilation (often $>7$ days) or severe multiple organ dysfunctions [2]. From this viewpoint, it should be important for ECMO centers to have a practical tool to determine the starting point of respiratory ECMO among candidates with different duration of MV. Technically, there are three common ways to reduce the risk of a prolonged MV before ECMO institution. The first is choosing an arbitrary deadline which is set according to general experiences, such as a 7 -day period [20]. The second is loosening the threshold value of PF ratio for ECMO from $100 \mathrm{mmHg}$ to $150 \mathrm{mmHg}$, as per the suggestion of ELSO Guidelines. The third is creating a risk assessment model for a multi-axial evaluation, as is our choice here.

What interested us was that the baseline PIP could not be identified as a prognostic predictor of adult respiratory 
Table 3 The serial changes of pressure settings of mechanical ventilation and index of arterial oxygenation during and after removal of venovenous extracorporeal membrane oxygenation

\begin{tabular}{|c|c|c|c|}
\hline & $\begin{array}{l}24 \mathrm{~h} \text { after ECMO institution } \\
\text { (T2) }\end{array}$ & $\begin{array}{l}\text { Just before ECMO removal. } \\
\text { (T3) }\end{array}$ & $\begin{array}{l}24 \mathrm{~h} \text { after ECMO removal } \\
\text { (T4) }\end{array}$ \\
\hline \multicolumn{4}{|l|}{ Survivors $(n=50)$} \\
\hline $\mathrm{P}_{\mathrm{a}} \mathrm{O}_{2} / \mathrm{F}_{\mathrm{i}} \mathrm{O}_{2}(\mathrm{mmHg})$ & $226 \pm 85^{*}$ & $206 \pm 89$ & $216 \pm 94$ \\
\hline Peak inspiratory pressure $\left(\mathrm{cmH}_{2} \mathrm{O}\right)$ & $30 \pm 5$ & $30 \pm 5$ & $24 \pm 13$ \\
\hline Mean airway pressure $\left(\mathrm{cmH}_{2} \mathrm{O}\right)$ & $17 \pm 3$ & $17 \pm 4$ & $17 \pm 4$ \\
\hline PEEP $(\mathrm{cmH} 2 \mathrm{O})$ & $12(10-14)$ & $10(10-12)$ & $12(10-12)$ \\
\hline Dynamic driving pressure $(\mathrm{cmH} 2 \mathrm{O})$ & $18 \pm 6$ & $19 \pm 5$ & $19 \pm 6$ \\
\hline Measured tidal volume (ml/kg) & $7 \pm 1$ & $8 \pm 2$ & $7 \pm 4$ \\
\hline Dynamic compliance $\left(\mathrm{ml} / \mathrm{cmH}_{2} \mathrm{O}\right)$ & $24 \pm 9^{*}$ & $28 \pm 12$ & $22 \pm 15$ \\
\hline Oxygen index & $8 \pm 4^{*}$ & $10 \pm 6$ & $10 \pm 6$ \\
\hline ECMO outflow $\mathrm{PaO}_{2}(\mathrm{mmHg})$ & $391(338-449)$ & $50(38-133)$ & - \\
\hline ECMO outflow $\mathrm{PaCO}_{2}(\mathrm{mmHg})$ & $35(28-40)$ & $40(36-59)$ & - \\
\hline ECMO outflow $\mathrm{O}_{2}$ saturation (\%) & 100 & 100 & - \\
\hline Non-Survivors $(n=56)$ & & & - \\
\hline $\mathrm{P}_{\mathrm{a}} \mathrm{O}_{2} / \mathrm{F}_{\mathrm{i}} \mathrm{O}_{2}(\mathrm{mmHg})$ & $164 \pm 84^{*}$ & - & - \\
\hline Peak inspiratory pressure $\left(\mathrm{cmH}_{2} \mathrm{O}\right)$ & $32 \pm 5$ & - & - \\
\hline Mean airway pressure $\left(\mathrm{cmH}_{2} \mathrm{O}\right)$ & $18 \pm 4$ & - & - \\
\hline PEEP $(\mathrm{cmH} 2 \mathrm{O})$ & $13 \pm 3$ & - & - \\
\hline Dynamic driving pressure $(\mathrm{cmH} 2 \mathrm{O})$ & $19 \pm 6$ & - & - \\
\hline Measured tidal volume (ml/kg) & $6 \pm 3$ & - & - \\
\hline Dynamic compliance $\left(\mathrm{ml} / \mathrm{cmH}_{2} \mathrm{O}\right)$ & $19 \pm 10^{*}$ & - & - \\
\hline Oxygen index ${ }^{c}$ & $14 \pm 7^{*}$ & - & - \\
\hline ECMO outflow $\mathrm{PaO}_{2}(\mathrm{mmHg})$ & $408 \pm 79$ & - & - \\
\hline ECMO outflow $\mathrm{PaCO}_{2}(\mathrm{mmHg})$ & $36 \pm 6$ & - & - \\
\hline ECMO outflow $\mathrm{O}_{2}$ saturation (\%) & 100 & - & - \\
\hline
\end{tabular}

Only the survivors showed data recorded just before and $24 \mathrm{~h}$ after ECMO removal

Data were presented as mean \pm standard deviation in normal-distributed numerical variables, median (interquartile range) in numerical variables not normaldistributed, and $\mathrm{n}(\%)$ in categorical variables. ECMO Extracorporeal membrane oxygenation, PEEP Positive end expiratory pressure

*The mean values of a specific variable in the T2 column are significant different between the survivors and non-survivors while analyzed by independent

T-test $(p<0.05)$

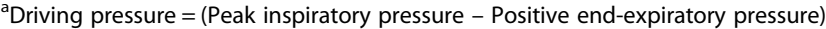

${ }^{b}$ Dynamic pulmonary compliance $=$ Measured tidal volume/ Driving pressure

${ }^{c}$ Oxygen index $=\left[\left(\right.\right.$ Mean airway pressure $\left.\square \times \square \mathrm{FiO}_{2} \square \times 100\right) /$ arterial oxygen tension $]$

ECMO in the current study, which was different from the suggestion of RESP score. The RESP score is derived from a retrospective analysis of 2355 adult patients in ELSO's registry and reveals that the baseline PIP, with a threshold value of $42 \mathrm{cmH}_{2} \mathrm{O}$, is a predictive factor for hospital mortality in adult patients receiving respiratory ECMO [11]. However, in the current study including 106 patients, the patients with a baseline $\mathrm{PIP}>42 \mathrm{~cm} \mathrm{H}_{2} \mathrm{O}(n=14)$ showed a significantly lower hospital mortality rate than the patients with a baseline PIP $\leq 42 \mathrm{~cm} \mathrm{H}_{2} \mathrm{O}(21 \%$ vs. $58 \%, p=0.02$ ). We thought that the discrepancy in sample size between the two studies should have some connection to this unexplained result. In the original study of RESP score [11], the odds ratio of baseline PIP for hospital survival is close to 1.0 (0.992). Furthermore, the medians of baseline PIP were surprisingly both the same (36 $\left.\mathrm{cmH}_{2} \mathrm{O}\right)$ in the survivors $(n=1338)$ and non-survivors $(n=1017)$. Therefore, the baseline PIP might not be a very suitable criterion to initiate respiratory ECMO. Some researchers suggest that the baseline plateau pressure $\left(\mathrm{P}_{\text {plat }}\right)$ is also a valuable indicator used for this purpose [21]. Although $\mathrm{P}_{\text {plat }}$ is a better airway pressure than PIP for measuring the pressure applied to lung itself during $\mathrm{MV}$, we were unable to reproduce the above-mentioned result because the data of $P_{\text {plat }}$ were severely incomplete in this retrospective study due to unknown reason.

Although the impact of the baseline pressure settings of MV remains equivocal on the outcomes of adult respiratory ECMO, an unreduced static or dynamic driving 


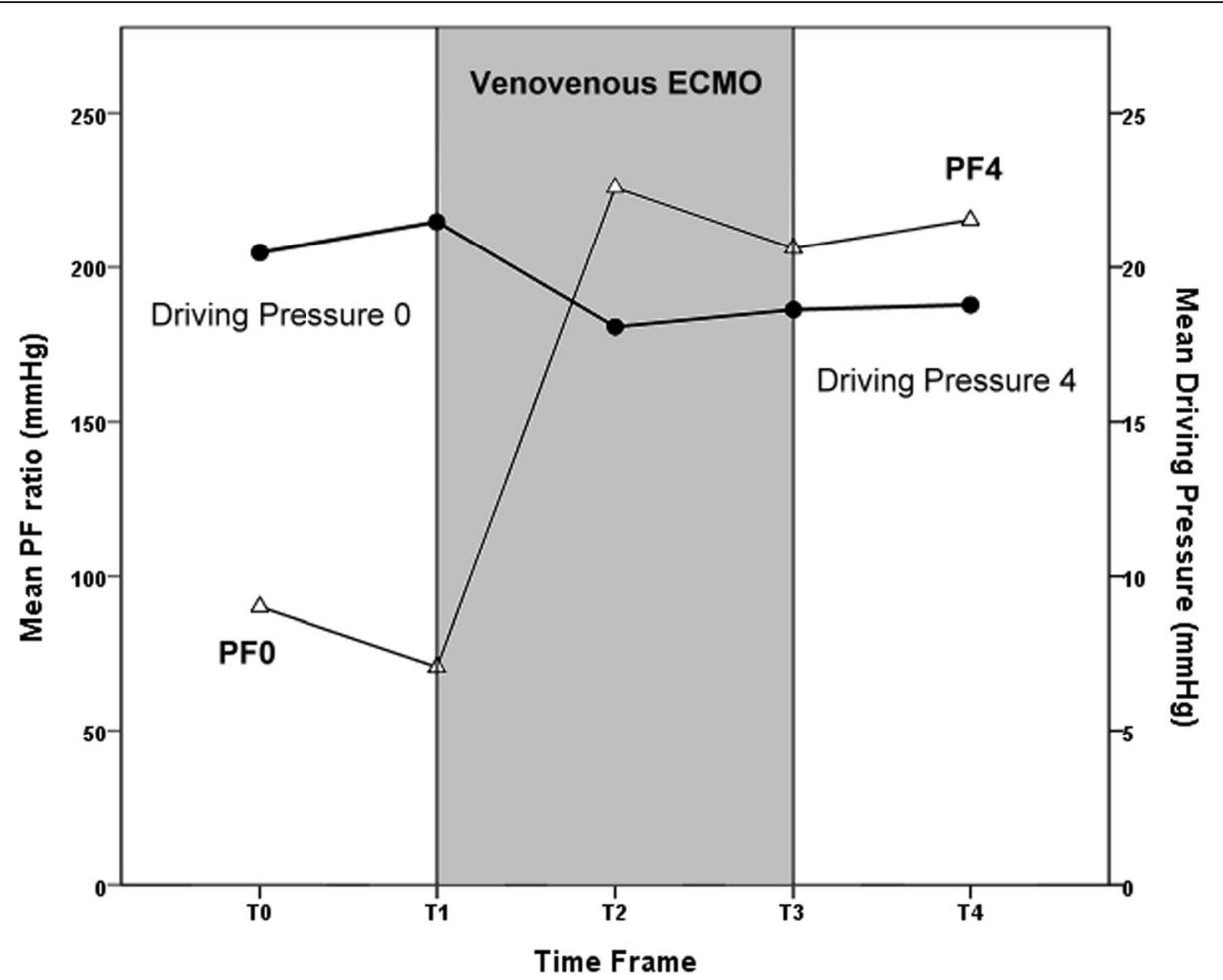

Fig. 3 Survivors' trends of $P F$ ratio and dynamic driving pressure during the support of $\mathrm{W}-E C M O$. $\left(T_{0}: 1-2 \mathrm{~h}\right.$ after intubation for $M V, T_{1}: 1-2 \mathrm{~h}$ before $\mathrm{ECMO}$ cannulation, $\mathrm{T}_{2}: 24 \mathrm{~h}$ after $\mathrm{ECMO}$ institution, $\mathrm{T}_{3}: 1-2 \mathrm{~h}$ before $\mathrm{ECMO}$ decannulation, and $\mathrm{T}_{4}: 24 \mathrm{~h}$ after $\mathrm{ECMO}$ removal)

pressure of MV during the first three days of adult respiratory ECMO is recently reported to be a predictor of hospital mortality in these ECMO-treated patients $[22,23]$. When the results of these updated investigations on adult respiratory ECMO are reviewed together, researchers may find that there seem to be some links among the duration of MV before ECMO institution, the driving pressure of MV during ECMO, and the outcomes of ECMO. According to Tables 2 and 3, all of the patients showed an improvement in arterial oxygenation and a downgrade of driving pressure of MV during the first $24 \mathrm{~h}$ of ECMO institution. Since the collapsed alveoli should be difficult to be re-opened by a decreased driving pressure, we could assume that the improvement in arterial oxygenation should depend on the oxygenator and the non-collapsed alveoli. However, as shown in fig. 3 , only patients maintaining the trend of improvement in arterial oxygenation throughout the ECMO support could eventually wean ECMO and survive. It is notably that the pulmonary compliance remained impaired in the survivors after a successful rescue of ECMO. These findings implied that the size of the non-collapsed pulmonary segments before ECMO should be one of the key contributors to the patient's progression on ECMO and the outcome. To keep the noncollapsed pulmonary segments opened under a reduced driving pressure during ECMO, the decrease in the driving pressure during the early support of ECMO was achieved by a reduction in PIP rather than in PEEP. Actually, choosing a moderate high PEEP is also an important issue in patients treated with lung-protective MV [17]. Despite not used in this study, an esophageal balloon is considered to be a useful tool to measure the serial changes of transpulmonary pressure and suggested an appropriate level of PEEP and driving pressure in this scenario [24]. In general, ventilating the patients with an unreduced driving pressure is not an effective solution to improve hypoxemia on VV-ECMO, since this behavior means that the clinicians still want to recruit the collapsed segments. In cases with a refractory hypoxemia during VV-ECMO, the circuit of ECMO should be rearranged to a hybrid configuration which may promptly correct the arterial hypoxemia and allow a decrease in driving pressure [25]. However, significant hypoxemia may recur during the weaning process of ECMO in any configuration if the pulmonary parenchyma is extensively damaged and the residual reservoir is below the requirement for surviving without ECMO.

The major limitations of this study are its retrospective design and moderate sample size. This study did not provide a comprehensive discussion of adult respiratory ECMO since only non-trauma patients treated with pressure-controlled ventilation and VV- 
ECMO in a single center were included. Further collaborative and prospective studies that adopt new techniques to obtain novel respiratory parameters in a large cohort of ECMO-treated ARDS patients are necessary to validate our hypothesis and determine the influences of baseline ventilator parameters on outcomes of adult respiratory ECMO.

\section{Conclusion}

Among the baseline ventilator parameters included in this study, duration of MV was the only parameter independently associated with hospital mortality in adult non-trauma patients treated with VV-ECMO. The benefit of VV-ECMO was small in patients with prolonged ventilation or severe multiple organ dysfunctions. Therefore, medical centers were suggested to find a suitable prognosticating tool to determine the starting point of respiratory ECMO among their candidates with different duration of MV.

\begin{abstract}
Abbreviations
AaDO2: Alveolar-arterial oxygen difference; APTT: Activated partial thromboplastin time; ARDS: Acute respiratory failure; ECMO: Extracorporeal membrane oxygenation; $\mathrm{FiO}_{2}$ : Fraction of inspiratory oxygen; LPV: Lungprotective ventilation; MV: Mechanical ventilation; Ol: Oxygen Index; $\mathrm{PaCO}_{2}$ : Arterial carbon dioxide tension; $\mathrm{PaO}_{2}$ : Arterial oxygen tension; PEEP: Positive end-expiratory pressure; PIP: Peak inspiratory pressure; PT: Prothrombin time; RV: Right ventricle; SaO2: Arterial oxygen saturation; SOFA: Sequential organ failure assessment; SpOz: Oxyhemoglobin saturation by pulse oximetry; VA: Venoarterial; VILI: Ventilator induced lung injury; W: Venovenous
\end{abstract}

\section{Acknowledgements}

We are grateful to all of the members in the ECMO Team and the Respiratory Support Group in Chang Gung Memorial Hospital for their feedback on the patient survey.

\section{Funding}

This study was supported by no funding.

\section{Availability of data and materials}

The data that support the findings of this study are available from Chang Gung Memorial Hospital but restrictions apply to the availability of these data, which were used under license for the current study, and so are not publicly available. Data are however available from the authors upon reasonable request and with permission of Chang Gung Memorial Hospital.

\section{Authors' contributions}

WMY contributed to the conception and design of the study, acquisition and interpretation of data, and revision of the manuscript. Y-SC also contributed to the revision of the manuscript. Both WMY and YSC had equal contribution to the final version of the manuscript (Co-first authors). HCC and LPJ contributed to the literature review and the formation of therapeutic protocol. WTI performed statistical analysis. WMY also contributed to manuscript composition and was responsible for the final product. All authors read and approved the final manuscript.

\section{Ethics approval and consent to participate}

The Chang Gung Medical Foundation Institutional Review Board (no. 201601483BO) approved the study and waived the requirement for informed consent due to the retrospective nature of this study.

\section{Consent for publication}

Not applicable.

\section{Competing interests}

None of the authors have a conflict of interest to declare in relation to this work.

\section{Publisher's Note}

Springer Nature remains neutral with regard to jurisdictional claims in published maps and institutional affiliations.

\section{Author details}

1Department of Cardiovascular Surgery, Chang Gung Memorial Hospital and Chang Gung University, Taoyuan, Taiwan. ${ }^{2}$ School of Traditional Chinese Medicine, Chang Gung University, Taoyuan, Taiwan. ${ }^{3}$ Department of Thoracic Medicine, Chang Gung Memorial Hospital and Chang Gung University, Taoyuan, Taiwan. ${ }^{4}$ Department of Obstetrics and Gynecology, School of Medicine, College of Medicine, Taipei Medical University, Taipei, Taiwan. ${ }^{5}$ Department of Obstetrics and Gynecology, Wan Fang Hospital, Taipei Medical University, Taipei, Taiwan.

Received: 30 April 2017 Accepted: 23 November 2017

Published online: 08 December 2017

\section{References}

1. Combes A, Brodie D, Bartlett R, Brochard L, Brower R, Conrad S, et al. Position paper for the organization of extracorporeal membrane oxygenation programs for acute respiratory failure in adult patients. Am J Respir Crit Care Med. 2014:190:488-96.

2. Fan E, Gattinoni L, Combes A, Schmidt M, Peek G, Brodie D, et al. Venovenous extracorporeal membrane oxygenation for acute respiratory failure : a clinical review from an international group of experts. Intensive Care Med. 2016:42:712-24

3. Thiagarajan RR, Barbaro RP, Rycus PT, Mcmullan DM, Conrad SA, Fortenberry $J \mathrm{D}$, et al. Extracorporeal life support organization registry international report 2016. ASAIO J. 2017:63:60-7.

4. Extracorporeal Life Support Organization (ELSO) Guidelines for Adult Respiratory Failure V1.3. 2013. https://www.elso.org/resources/guidelines. aspx. Accessed 1 Jan 2017

5. MY W, Huang CC, TI W, Wang CL, Lin PJ. Venovenous extracorporeal membrane oxygenation for acute respiratory distress syndrome in adults: prognostic factors for outcomes. Medicine (Baltimore). 2016;95:e2870.

6. Tsai $H C$, Chang $C H$, Tsai FC, Fan PC, Juan $K C$, Lin CY, et al. Acute respiratory distress syndrome with and without extracorporeal membrane oxygenation: a score matched study. Ann Thorac Surg. 2015;100:458-64.

7. Cheng YT, MY W, Chang YS, Huang CC, Lin PJ. Developing a simple preinterventional score to predict hospital mortality in adult venovenous extracorporeal membrane oxygenation: a pilot study. Medicine (Baltimore). 2016;95:e4380

8. Chiu LC, Tsai FC, HC H, Chang CH, Hung CY, Lee CS, et al. Survival predictors in acute respiratory distress syndrome with extracorporeal membrane oxygenation. Ann Thorac Surg. 2015;99:243-50.

9. MY W, Lin PJ, Tseng YH, Kao KC, Hsiao HL, Huang CC. Venovenous extracorporeal life support for posttraumatic respiratory distress syndrome in adults: the risk of major hemorrhages. Scand J Trauma Resusc Emerg Med. 2014;22:56.

10. Vincent JL, Moreno R, Takala J, Willatts S, De Mendonça A, Bruining H, et al. The SOFA (sepsis-related organ failure assessment) score to describe organ dysfunction/failure. Intensive Care Med. 1996;22:707-10.

11. Schmidt M, Bailey M, Sheldrake J, Hodgson C, Aubron C, Rycus PT, et al. Predicting survival after extracorporeal membrane oxygenation for severe acute respiratory failure. The respiratory extracorporeal membrane oxygenation survival prediction (RESP) score. Am J Respir Crit Care Med. 2014;189:1374-82.

12. Livingston BM, Mackenzie SJ, MacKirdy FN, Howie JC. Should the presedation Glasgow coma scale value be used when calculating acute physiology and chronic health evaluation scores for sedated patients? Scottish Intensive Care Society audit group. Crit Care Med. 2000;28:389-94.

13. Peek GJ, Mugford M, Tiruvoipati R, Wilson A, Allen E, Thalanany MM, et al. Efficacy and economic assessment of conventional ventilatory support versus extracorporeal membrane oxygenation for severe adult respiratory failure (CESAR): a multicentre randomised controlled trial. Lancet. 2009: 374:1351-63. 
14. Galetke W, Feier C, Muth T, Ruehle KH, Borsch-Galetke E, Randerath W. Reference values for dynamic and static pulmonary compliance in men Respir Med. 2007;101:1783-9.

15. Carney D, DiRocco J, Nieman G. Dynamic alveolar mechanics and ventilatorinduced lung injury. Crit Care Med. 2005;33:S122-S8.

16. Barbas CS, de Matos GF, Pincelli MP, da Rosa Borges E, Antunes T, de Barros $J \mathrm{M}$, et al. Mechanical ventilation in acute respiratory failure: recruitment and high positive end-expiratory pressure are necessary. Curr Opin Crit Care. 2005;11:18-28

17. Rouby JJ, Liu Q, Goldstein I. Selecting the right level of positive endexpiratory pressure in patients with acute respiratory distress syndrome. Am J Respir Crit Care Med. 2002;165:1182-6.

18. Gattinoni L, Caironi P, Cressoni M, Chiumello D, Ranieri VM, Quintel M, et al. Lung recruitment in patients with the acute respiratory distress syndrome. N Engl J Med. 2006:354:1175-86.

19. Boissier F, Katsahian S, Razazi K, Thille AW, Roche-Campo F, Leon R, et al. Prevalence and prognosis of cor pulmonale during protective ventilation for acute respiratory distress syndrome. Intensive Care Med. 2013;39:1725-33.

20. Bohman JK, Vogt MN, Hyder JA. Retrospective report of contraindications to extracorporeal membrane oxygenation (ECMO) among adults with acute respiratory distress syndrome (ARDS). Heart Lung. 2016;45:227-31.

21. Schmidt M, Zogheib E, Roze H, Repesse X, Lebreton G, Luyt CE, et al. The PRESERVE mortality risk score and analysis of long-term outcomes after extracorporeal membrane oxygenation for severe acute respiratory distress syndrome. Intensive Care Med. 2013;39:1704-13.

22. Serpa Neto A, Schmidt M, Azevedo LC, Bein T, Brochard L, Beutel G, et al. Associations between ventilator settings during extracorporeal membrane oxygenation for refractory hypoxemia and outcome in patients with acute respiratory distress syndrome: a pooled individual patient data analysis : mechanical ventilation during ECMO. Intensive Care Med. 2016;42:1672-84.

23. Chiu $\mathrm{LC}, \mathrm{HC}$ H, Hung $\mathrm{CY}$, Chang $\mathrm{CH}$, Tsai $F C$, Yang $\mathrm{CT}$, et al. Dynamic driving pressure associated mortality in acute respiratory distress syndrome with extracorporeal membrane oxygenation. Ann Intensive Care. 2017;7:12

24. Talmor D, Sarge T, Malhotra A, O'Donnell CR, Ritz R, Lisbon A, et al. Mechanical ventilation guided by esophageal pressure in acute lung injury. N Engl J Med. 2008;359:2095-104.

25. Montisci A, Maj G, Zangrillo A, Winterton D, Pappalardo F. Management of refractory hypoxemia during venovenous extracorporeal membrane oxygenation for ARDS. ASAIO J. 2015;61:227-36.

\section{Submit your next manuscript to BioMed Central and we will help you at every step:}

- We accept pre-submission inquiries

- Our selector tool helps you to find the most relevant journal

- We provide round the clock customer support

- Convenient online submission

- Thorough peer review

- Inclusion in PubMed and all major indexing services

- Maximum visibility for your research

Submit your manuscript at www.biomedcentral.com/submit

) Biomed Central 